\title{
Baseline Serum Concentrations of TRAIL in Early Rheumatoid Arthritis: Relationship with Response to Disease-modifying Antirheumatic Drugs
}

\author{
PAOLA SECCHIERO, FEDERICA CORALLINI, GABRIELLA CASTELLINO, ALESSANDRA BORTOLUZZI, \\ LORENZO CARUSO, SERENA BUGATTI, RAFFAELLA BOSCO, MAURIZIO MONTECUCCO, and FRANCESCO TROTTA
}

\begin{abstract}
Objective. To assess the relationship between serum concentrations of tumor necrosis factor (TNF)-related apoptosis-inducing ligand (TRAIL) and osteoprotegerin (OPG) and the therapeutic response to disease-modifying antirheumatic drugs (DMARD) in patients with early rheumatoid arthritis (RA).

Methods. Circulating levels of TRAIL and its soluble receptor OPG were measured by ELISA in paired serum samples obtained from 66 patients with early RA at their first visit (baseline) and after 1 year of therapy. Levels of TRAIL and OPG were analyzed in relation to the clinical response, defined by the 28-joint count Disease Activity Score (DAS28).

Results. Both serum TRAIL and OPG increased after DMARD therapy. Baseline levels of TRAIL, but not OPG, were significantly higher $(\mathrm{p}<0.05)$ in the patients that achieved a clinical response by DAS28 after 1 year of therapy, versus patients without clinical response to DMARD. Baseline serum levels of TRAIL were higher $(\mathrm{p}<0.01)$ in rheumatoid factor-negative patients.

Conclusion. Our data suggest that the basal level of circulating TRAIL is an important determinant in the therapeutic response to DMARD in patients with early RA. (First Release May 15 2010; J Rheumatol 2010;37:1461-6; doi:10.3899/jrheum.091363)
\end{abstract}

Key Indexing Terms:

EARLY RHEUMATOID ARTHRITIS DISEASE MODIFYING ANTIRHEUMATIC DRUGS TUMOR NECROSIS FACTOR RELATED APOPTOSIS INDUCING LIGAND

Early diagnosis of rheumatoid arthritis (RA) is crucial to prevent unfavorable disease outcome ${ }^{1}$. RA treatment includes early use of disease-modifying antirheumatic drugs (DMARD) such as methotrexate (MTX), leflunomide, sulfasalazine (SSZ), and hydroxychloroquine, and, for the most aggressive disease subsets, biologic agents initiated as soon

From the Department of Morphology and Embryology, and the Rheumatology Section, Department of Clinical and Experimental Medicine, University of Ferrara, Ferrara, Italy; and the Department of Rheumatology, IRCCS Policlinico S. Matteo, University of Pavia, Pavia, Italy.

Supported by grants from the Fondo Regione Emilia Romagna (PG 08 23943/2008/P18A4) and CariFe Foundation.

P. Secchiero, PhD; F. Corallini, PhD, Department of Morphology and Embryology; G. Castellino, MD; A. Bortoluzzi, MD, Rheumatology Section, Department of Clinical and Experimental Medicine; L. Caruso, PhD, Department of Morphology and Embryology, University of Ferrara; S. Bugatti, MD, Department of Rheumatology, IRCCS Policlinico S. Matteo, University of Pavia; R. Bosco, PhD, Department of Morphology and Embryology, University of Ferrara; M. Montecucco, MD, Department of Rheumatology, IRCCS Policlinico S. Matteo, University of Pavia;

F. Trotta, MD, Rheumatology Section, Department of Clinical and

Experimental Medicine, University of Ferrara.

Dr. Secchiero and Dr. Corallini contributed equally to this report. Address correspondence to Dr. F. Corallini, Department of Morphology and Embryology, University of Ferrara, Via Fossato di Mortara 70, 44100 Ferrara, Italy.E-mail:federica.corallini@unife.it

Accepted for publication February 16, 2010. as the diagnosis is confirmed. To achieve remission, optimal management of RA is needed within 3-6 months after onset of disease ${ }^{2}$.

Tumor necrosis factor (TNF)-related apoptosis-inducing ligand (TRAIL), also known as Apo-2 ligand, is a member of the structurally related TNF family of cytokines, and exists as either a type II membrane protein or as a soluble protein $^{3}$. Four transmembrane TRAIL receptors belonging to the apoptosis-inducing TNF-receptor (R) family have been described. While TRAIL-R1 (DR4) and TRAIL-R2 (DR5) transduce apoptotic signals upon binding of TRAIL, TRAIL-R3 (DcR1) and TRAIL-R4 (DcR2) are homologous to DR4 and DR5 in their cysteine-rich extracellular domain, but lack intracellular death domain and apoptosis-inducing capability $^{3}$. In addition, it has recently been shown that the soluble receptor osteoprotegerin (OPG) interacts with and neutralizes the biological activity of TRAIL with affinity comparable to that of RANKL, another member of the TNF family of cytokines ${ }^{4}$. Various in vitro and in vivo studies in animal models have shown that TRAIL might have a therapeutic role in ameliorating experimental osteoarthritis, as well as in promoting apoptosis of synovial fibroblasts obtained from patients with $\mathrm{RA}^{5-10}$. To date, limited data are available on the levels of circulating TRAIL in RA patients. Moreover, although it has been shown that TRAIL is able to

Personal non-commercial use only. The Journal of Rheumatology Copyright (C) 2010. All rights reserved. 
induce apoptosis of RA-derived synoviocytes ${ }^{7-10}$, it is noteworthy that TRAIL can also promote nonapoptotic signals in a cell type-dependent manner ${ }^{11-18}$. In particular, it has been demonstrated that recombinant TRAIL can also induce in vitro proliferation of RA-derived synoviocytes surviving the initial induction of apoptosis ${ }^{11,14}$; another study proposed that high levels of OPG might inhibit the ability of TRAIL to induce apoptosis of RA-derived synoviocytes ${ }^{10}$.

The aim of our study was to measure serum concentrations of TRAIL and OPG in patients with early RA and to assess the relationship between levels of TRAIL and OPG and the therapeutic response to DMARD, defined on the basis of the 28-joint count Disease Activity Score (DAS28).

\section{MATERIALS AND METHODS}

Patients. All patients presenting with early arthritis between January 2006 and January 2008 were included in the study cohort. "Early arthritis" was defined by the presence of 2 of the following 4 clinical criteria: no antecedent trauma, at least one tender joint, at least one swollen joint, and morning stiffness lasting $\geq 60$ minutes. In addition, inclusion criteria included serological signs of inflammation [elevated erythrocyte sedimentation rate (ESR) or C-reactive protein (CRP)] or rheumatoid factor (RF) positivity and anticitrullinated protein antibodies (anti-CCP) and a symptom duration not longer than 24 weeks. Clinical assessment of patients included evaluation by DAS28 and the Health Assessment Questionnaires (HAQ). Venous serum was obtained from each patient. All patients were treated with DMARD therapy, consisting of a single DMARD (with or without steroids) or combination DMARD (Table 1). Paired serum samples were available for each patient: one sample obtained at baseline (before starting DMARD therapy) and a second sample after about 1 year of therapy. In these patients, at 1 year followup, a decrease in DAS28 $>1.2$ with respect to baseline was defined as clinical response to treatment, while increase or decrease in DAS2 $8<1.2$ was defined as no response, as reported ${ }^{19}$. The laboratory and clinical information for each patient was obtained from clinical records. As a control group, sera were collected from 51 age- and sex-matched healthy donors (age $59.3 \pm 13.8 \mathrm{yrs} ; 70.6 \%$ were female).

Written consent for all procedures was obtained from all subjects in accord with the Declaration of Helsinki and with approval obtained from the institutional review boards of the university hospitals of Ferrara and Pavia.

Measurement of TRAIL and OPG. Measurement of TRAIL and OPG was

Table 1. Characteristics of the study population.

\begin{tabular}{|c|c|}
\hline Variables & $\begin{array}{l}\text { Patients with Early RA, } \\
\qquad \mathrm{n}=66\end{array}$ \\
\hline Age, yrs* & $60.1 \pm 15.1$ \\
\hline Female, $\%^{\dagger}$ & 71.9 \\
\hline Disease duration, $\mathrm{mo}^{*}$ & $12 \pm 1$ \\
\hline RF-positive at baseline, $\%^{\dagger}$ & 40.7 \\
\hline Anti-CCP-positive at baseline, $\%^{\dagger}$ & 26.9 \\
\hline Erosive disease at baseline, $\%^{\dagger}$ & 49.1 \\
\hline \multicolumn{2}{|l|}{ Taking medications, $\%^{\dagger}$} \\
\hline Methotrexate & 4.4 \\
\hline Methotrexate + steroids & 76.3 \\
\hline Methotrexate + hydroxychloroquine & 10.9 \\
\hline Hydroxychloroquine + steroids & 8.4 \\
\hline
\end{tabular}

$*$ Mean $\pm \mathrm{SD} ;{ }^{\dagger}$ percentage of positive patients. RF: rheumatoid factor; CCP: citric citrullinated peptide. carried out in the serum samples of patients with early RA and healthy controls. Analyses were performed using specific commercial ELISA kits purchased from R\&D Systems (Minneapolis, MN, USA) and Alexis Biochemicals (Lausen, Switzerland) for TRAIL and OPG, respectively. Assays were carried out in duplicate in accord with the manufacturer's instructions and analyzed with an ELISA reader at $450 \mathrm{~nm}$. Sensitivity of the TRAIL assay was $2.9 \mathrm{pg} / \mathrm{ml}$ and the intra- and interassay coefficients of variation $(\mathrm{CV})$ were $3.9 \%$ and $6 \%$, respectively, while the sensitivity of the OPG assay was $2.8 \mathrm{pg} / \mathrm{ml}$ and intra- and interassay $\mathrm{CV}$ were $9 \%$ and $<10 \%$.

Statistical analysis. Data were calculated and shown as mean \pm SD or as median and interquartile range (IQR), according to the distribution. Comparisons between patient groups and controls were performed with Student's t test and chi-square test. Differences in TRAIL, OPG, and disease variables across phases of the study were analyzed by ANOVA for repeated measures. Statistical significance was defined as $\mathrm{p}<0.05$.

\section{RESULTS}

Levels of TRAIL and OPG increased after therapy. Demographic and clinical characteristics of 66 early RA patients analyzed for serum TRAIL and OPG levels are given in Table 1. At baseline (before starting DMARD therapy), the RA patient group was characterized by $66 \%$ positivity of CRP, mean DAS28 score $5.07 \pm 1.68$, mean HAQ score $1.31 \pm 0.8$, total swollen joint count $10.2 \pm 6.5$, and tender joint count $10.2 \pm 8.4$.

Levels of serum TRAIL in RA patients at baseline (mean $65.3 \pm 24.4 \mathrm{pg} / \mathrm{ml}$ ) were comparable to those in healthy controls (mean $68.6 \pm 20.6 \mathrm{pg} / \mathrm{ml}$ ); after 1 year of DMARD therapy, followup analysis of the same RA patients showed a significant increase $(\mathrm{p}<0.01)$ in serum levels of TRAIL compared to baseline levels in patients and controls (Figure 1A). Also, levels of serum OPG in RA patients at baseline (mean $79.4 \pm 44 \mathrm{pg} / \mathrm{ml}$ ) were comparable with those in controls (mean $74.8 \pm 26.6 \mathrm{pg} / \mathrm{ml}$ ), and 1 year after DMARD therapy serum levels of OPG were significantly increased compared to those in controls ( $\mathrm{p}<0.05$ ), but not compared to baseline levels of OPG in RA patients ( $\mathrm{p}=0.14$; Figure $1 \mathrm{~B})$.

Baseline serum TRAIL but not OPG levels predict clinical response to therapy. After 1 year, significant decreases in the DAS28 score and HAQ score and in the percentage of CPR-positive patients were observed in the early RA population (Figure 2). Interestingly, when the RA population was subdivided into responders and nonresponders to DMARD therapy on the basis of differences in DAS28 score (delta DAS28, Figure 3A), we observed that the patients showing a good response to DMARD therapy had significantly higher levels $(\mathrm{p}<0.05)$ of baseline serum TRAIL compared to patients whose delta DAS28 showed minimal $(<1.2)$ or absent variation after therapy (Figure 3B). In contrast, no significant differences were observed in baseline serum OPG levels between these 2 groups of patients (Figure 3B).

Since these findings suggest that high baseline serum levels of TRAIL, but not OPG, might have predictive value in identifying those patients that would show a favorable response to DMARD, we examined further the baseline levels of serum TRAIL and OPG in relation to negative 

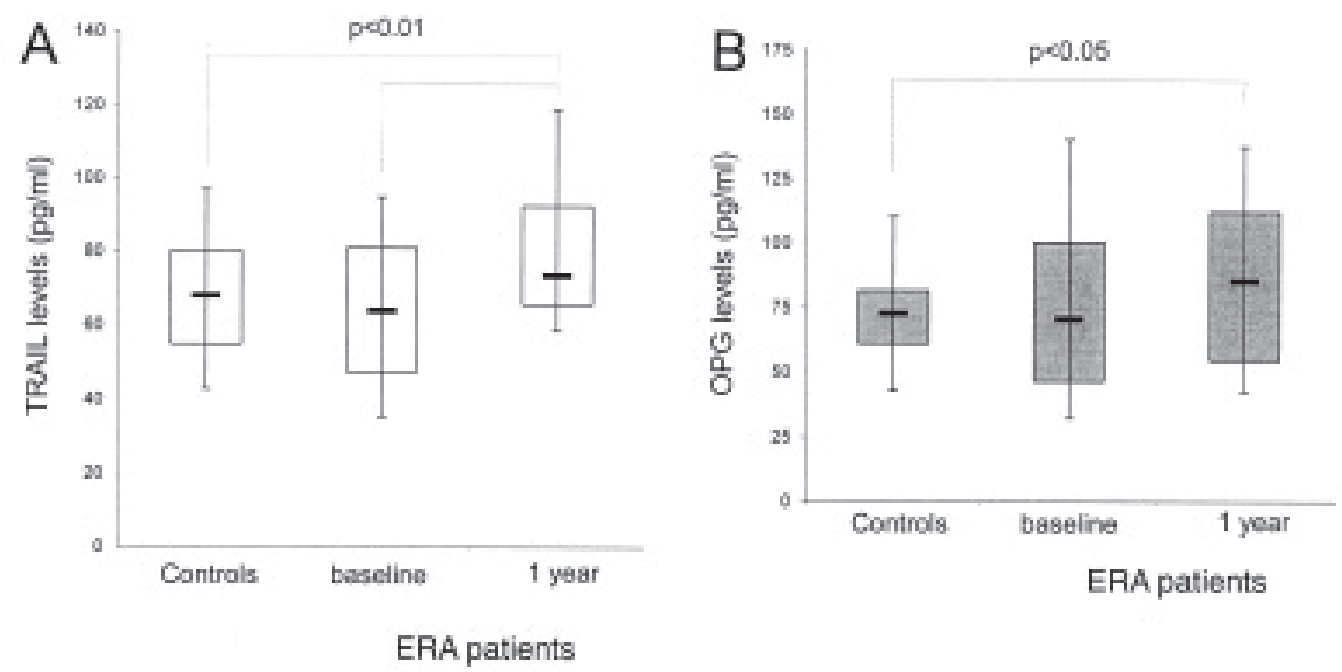

Figure 1. Comparison of levels of circulating TRAIL (A) and OPG (B) in controls and patients with early RA, determined by ELISA. Patient samples were collected at baseline, i.e., before starting therapy, and again after 1 year of DMARD therapy. Horizontal bars are median, upper and lower edges of box are 75th and 25th percentiles, extensions are 10th and 90th percentiles.
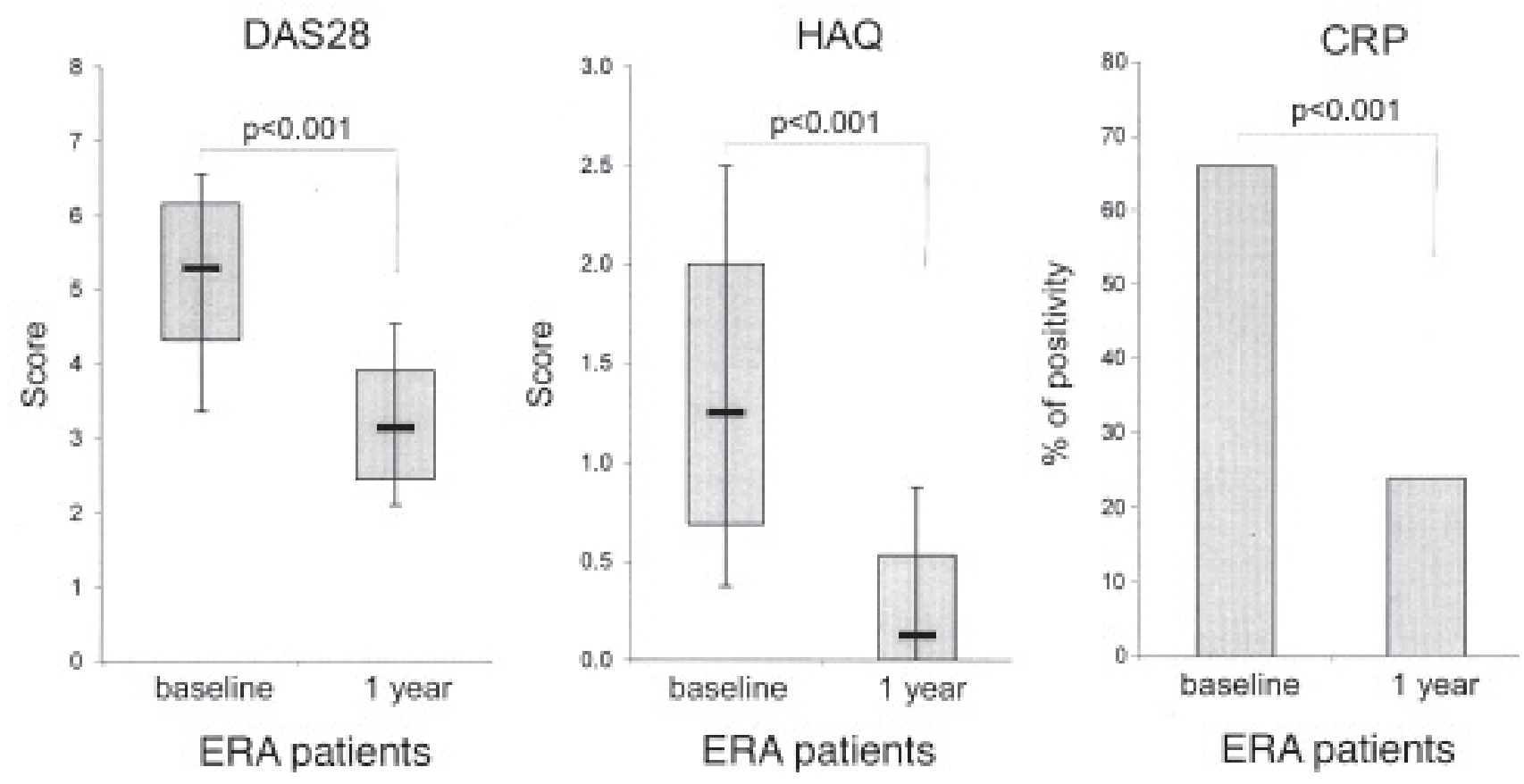

Figure 2. Clinical response of patients with early RA after 1 year of DMARD therapy. DAS28 and HAQ scores and positivity for CRP were monitored at baseline (before starting therapy) and after 1 year of DMARD therapy. For DAS28 and HAQ scores, horizontal bars are median, upper and lower edges of box are 75th and 25th percentiles, extensions are 10th and 90th percentiles. Percentages of patients positive for CRP at the 2 timepoints are shown.

prognostic factors, such as presence of erosive disease (Figure 4A) and RF positivity (Figure 4B). Interestingly, while serum levels of OPG were significantly higher $(\mathrm{p}<$ 0.01 ) in patients with erosive disease, serum levels of TRAIL were not significantly different in patients with and those without erosive bone disease (Figure 4A). On the other hand, serum levels of TRAIL were significantly lower ( $p<0.01$ ) in patients positive for RF (Figure 4B), in keeping with a role of TRAIL in counteracting autoimmune phenomena ${ }^{3}$. 

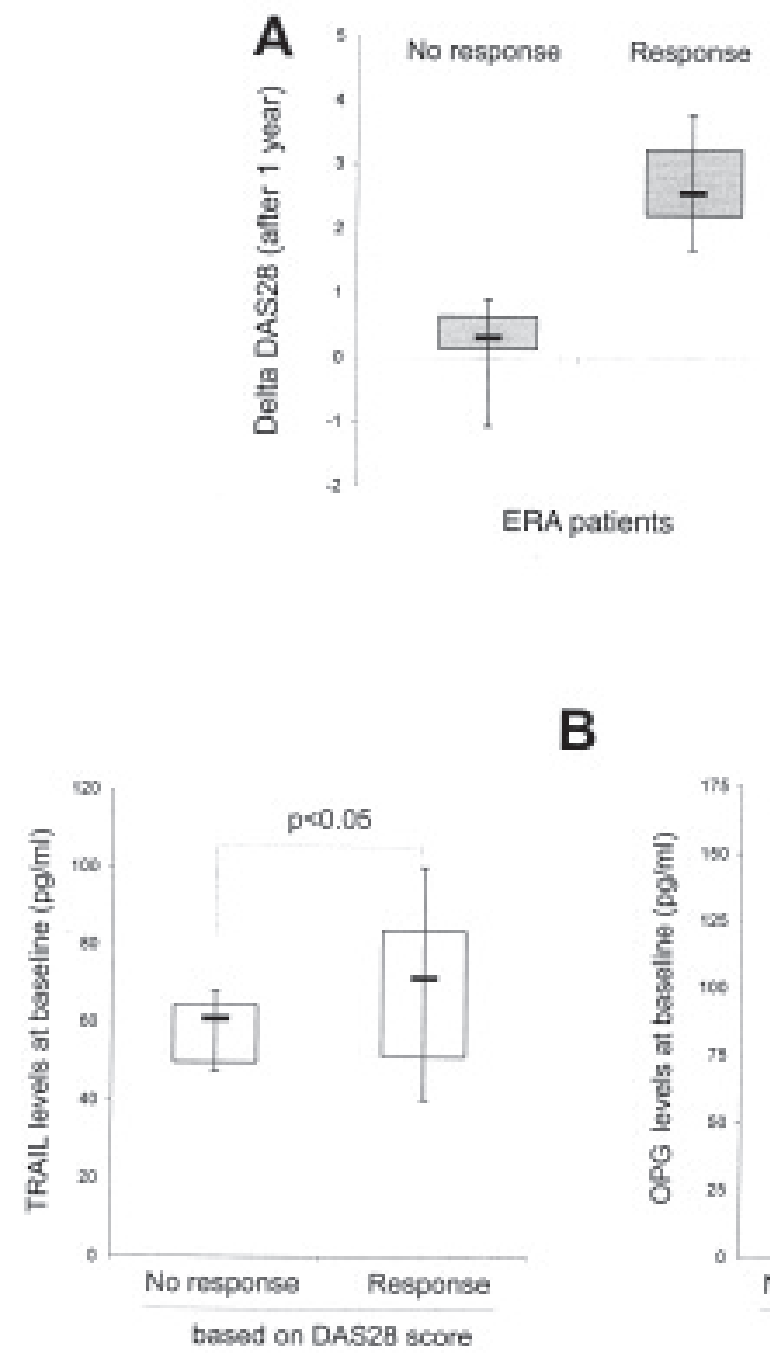

B

Figure 3. Circulating TRAIL and OPG levels in patients with early RA in relationship to their clinical response to DMARD therapy. A. Patients were divided into DMARD responders and non-responders on the basis of delta DAS28. B. Serum levels of TRAIL and OPG in patients at baseline compared to clinical response to DMARD. Horizontal bars are median, upper and lower edges of box are 75th and 25th percentiles, extensions are 10th and 90th percentiles.

\section{DISCUSSION}

A major finding of our study is that patients with higher levels of serum TRAIL, irrespective of their disease activity score at baseline, obtained the optimal response from DMARD therapy. On the other hand, pretreatment levels of serum OPG did not predict clinical outcome in our study population. In this respect, although data concerning the levels of OPG in sera of patients with early RA are heterogeneous $^{20-25}$, a possible pathogenic link between elevated levels of OPG and inflammation has been suggested by in vitro studies ${ }^{26-28}$. However, as in disorders of elevated bone turnover ${ }^{29}$, the upregulation of OPG could also represent a compensatory mechanism to limit bone erosion. We observed consistently higher basal serum OPG levels in patients with erosive disease.
Moreover, we found that serum levels of OPG as well as TRAIL increased in response to DMARD therapy. These findings are in agreement with reports from in vitro studies that therapy with MTX and SSZ each augmented the secretion of $\mathrm{OPG}^{30}$. In addition, serum OPG and TRAIL were both higher after 1 year of DMARD therapy in patients with a good clinical response. In this respect, it is noteworthy that although OPG is able to potentially interact with TRAIL, and both OPG and TRAIL display antiosteoclastic activi$\mathrm{ty}^{31,32}$, we have recently shown that when added in vitro at a 1:1 (TRAIL:OPG) ratio, the antiosteoclastic activity of OPG is not impaired by the presence of TRAIL ${ }^{33}$. Further, it should be considered that while we measured concentrations of OPG, which are particularly elevated in the synovial fluid of RA patients (mean $667.3 \pm 424.5 \mathrm{pg} / \mathrm{ml}$ ), in keeping with

Personal non-commercial use only. The Journal of Rheumatology Copyright (C 2010. All rights reserved. 

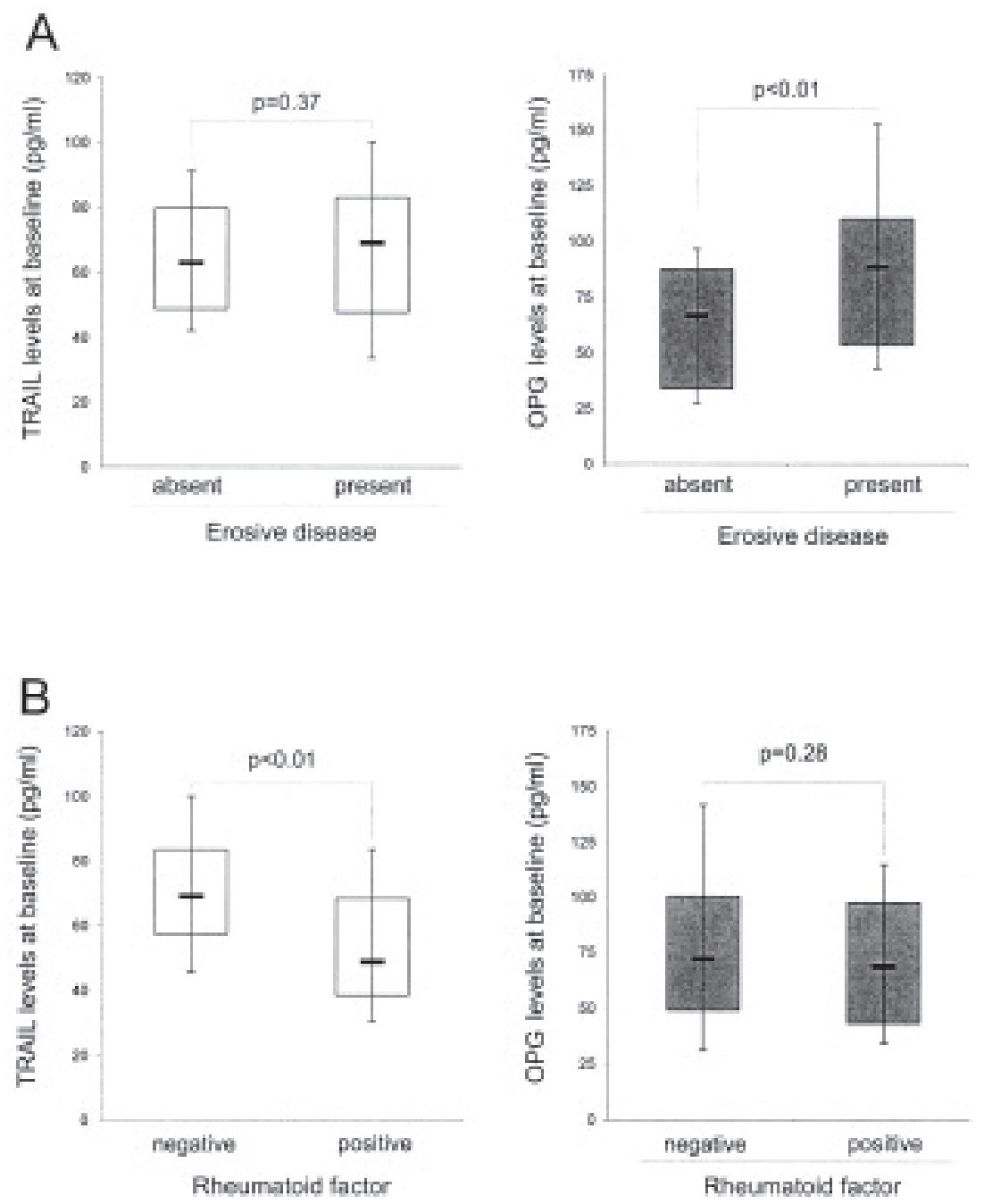

Figure 4. Circulating TRAIL and OPG levels in patients with early RA at baseline in relationship to negative prognostic markers: A. presence or absence of erosive disease; B. rheumatoid factor status. Horizontal bars are median, upper and lower edges of box are 75th and 25th percentiles, extensions are 10th and 90th percentiles.

a potential antierosive role of synovial OPG, we were unable to detect soluble TRAIL in the same synovial fluids (with assay sensitivity of $2.9 \mathrm{pg} / \mathrm{ml}$ ), strongly suggesting that the potential biological activity of soluble TRAIL is not expressed at the synovial level.

The major finding of our study was that higher concentrations of serum TRAIL at baseline were observed in patients with early RA with a favorable response to DMARD therapy, and that TRAIL might induce its immunomodulatory activity at the systemic level.

\section{REFERENCES}

1. Scott DL, Steer S. The course of established rheumatoid arthritis. Best Pract Res Clin Rheumatol 2007;21:943-67.

2. Pasero G, Priolo F, Marubini E, Fantini F, Ferraccioli G, Magaro $\mathrm{M}$, et al. Slow progression of joint damage in early rheumatoid arthritis treated with cyclosporin A. Arthritis Rheum 1996; 39:1006-15.
3. Zauli G, Secchiero P. The role of the TRAIL/TRAIL-receptors system in hematopoiesis and endothelial cell biology. Cytokine Growth Factor Rev 2006; 17:245-57.

4. Vitovski S, Phillips JS, Sayers J, Croucher PI. Investigating the interaction between osteoprotegerin and RANKL or TRAIL: evidence for a pivotal role for osteoprotegerin in regulating two distinct pathways. J Biol Chem 2007;282:31601-9.

5. Song K, Chen Y, Göke R, Wilmen A, Seidel C, Göke A, et al. Tumor necrosis factor-related apoptosis-inducing ligand (TRAIL) is an inhibitor of autoimmune inflammation and cell cycle progression. J Exp Med 2000;191:1095-104.

6. Liu Z, Xu X, Hsu HC, Tousson A, Yang PA, Wu Q, et al. CII-DC-AdTRAIL cell gene therapy inhibits infiltration of CII-reactive T cells and CII-induced arthritis. J Clin Invest 2003;112:1332-41.

7. Ichikawa K, Liu W, Fleck M, Zhang H, Zhao L, Ohtsuka T, et al. TRAIL-R2 (DR5) mediates apoptosis of synovial fibroblasts in rheumatoid arthritis. J Immunol 2003;171:1061-9.

8. Yao Q, Seol DW, Mi Z, Robbins PD. Intra-articular injection of recombinant TRAIL induces synovial apoptosis and reduces 
inflammation in a rabbit knee model of arthritis. Arthritis Res Ther 2006;8:R16.

9. Miranda-Carús ME, Balsa A, Benito-Miguel M, De Ayala CP, Martín-Mola E. Rheumatoid arthritis synovial fluid fibroblasts express TRAIL-R2 (DR5) that is functionally active. Arthritis Rheum 2004;50:2786-93.

10. Miyashita T, Kawakami A, Nakashima T, Yamasaki S, Tamai M, Tanaka F, et al. Osteoprotegerin (OPG) acts as an endogenous decoy receptor in tumour necrosis factor-related apoptosis-inducing ligand (TRAIL)-mediated apoptosis of fibroblast-like synovial cells. Clin Exp Immunol 2004;137:430-6.

11. Morel J, Audo R, Hahne M, Combe B. Tumor necrosis factor-related apoptosis-inducing ligand (TRAIL) induces rheumatoid arthritis synovial fibroblast proliferation through mitogen-activated protein kinases and phosphatidylinositol 3-kinase/Akt. J Biol Chem 2005;280:15709-18.

12. Secchiero P, Zerbinati C, Rimondi E, Corallini F, Milani D, Grill V, et al. TRAIL promotes the survival, migration and proliferation of vascular smooth muscle cells. Cell Mol Life Sci 2004;61:1965-74.

13. Audo R, Combe B, Coulet B, Morel J, Hahne M. The pleiotropic effect of TRAIL on tumor-like synovial fibroblasts from rheumatoid arthritis patients is mediated by caspases. Cell Death Differ 2009;16:1227-37.

14. Pundt N, Peters MA, Wunrau C, Strietholt S, Fehrmann C, Neugebauer K, et al. Susceptibility of rheumatoid arthritis synovial fibroblasts to FasL- and TRAIL-induced apoptosis is cell cycle-dependent. Arthritis Res Ther 2009;11:R16.

15. Secchiero P, Gonelli A, Mirandola P, Melloni E, Zamai L, Celeghini $\mathrm{C}$, et al. Tumor necrosis factor-related apoptosis-inducing ligand induces monocytic maturation of leukemic and normal myeloid precursors through a caspase-dependent pathway. Blood 2002;100:2421-9.

16. Milani D, Zauli G, Rimondi E, Celeghini C, Marmiroli S, Narducci $\mathrm{P}$, et al. Tumour necrosis factor-related apoptosis-inducing ligand sequentially activates pro-survival and pro-apoptotic pathways in SK-N-MC neuronal cells. J Neurochem 2003;86:126-35.

17. Zauli G, Pandolfi A, Gonelli A, Di Pietro R, Guarnieri S, Ciabattoni $\mathrm{G}$, et al. TNF-related apoptosis-inducing ligand (TRAIL) sequentially up-regulates nitric oxide and prostanoid production in primary human endothelial cells. Circ Res 2003;92:732-40.

18. Secchiero P, Corallini F, di Iasio MG, Gonelli A, Barbarotto E, Zauli G. TRAIL counteracts the proadhesive activity of inflammatory cytokines in endothelial cells by down-modulating CCL8 and CXCL10 chemokine expression and release. Blood 2005;105:3413-9.

19. González-Alvaro I, Ortiz AM, Tomero EG, Balsa A, Orte J, Laffon A, et al. Baseline serum RANKL levels may serve to predict remission in rheumatoid arthritis patients treated with TNF antagonists. Ann Rheum Dis 2007;66:1675-8.

20. Haynes D, Crotti T, Weedon H, Slavotinek J, Au V, Coleman M, et al. Modulation of RANKL and osteoprotegerin expression in synovial tissue from patients with rheumatoid arthritis in response to disease-modifying antirheumatic drug treatment and correlation with radiologic outcome. Arthritis Rheum 2008;59:911-20.
21. Ziolkowska M, Kurowska M, Radzikowska A, Luszczykiewicz G, Wiland P, Dziewczopolski W, et al. High levels of osteoprotegerin and soluble receptor activator of nuclear factor kappa B ligand in serum of rheumatoid arthritis patients and their normalization after anti-tumor necrosis factor alpha treatment. Arthritis Rheum 2002;46:1744-53.

22. Asanuma Y, Chung CP, Oeser A, Solus JF, Avalos I, Gebretsadik T, et al. Serum osteoprotegerin is increased and independently associated with coronary-artery atherosclerosis in patients with rheumatoid arthritis. Atherosclerosis 2007;195:e135-41.

23. Vandooren B, Cantaert T, Noordenbos T, Tak PP, Baeten D. The abundant synovial expression of the RANK/RANKL/ osteoprotegerin system in peripheral spondylarthritis is partially disconnected from inflammation. Arthritis Rheum 2008;58:718-29.

24. Hein GE, Meister M, Oelzner P, Franke S. sRANKL and OPG in serum and synovial fluid of patients with rheumatoid arthritis in comparison to non-destructive chronic arthritis. Rheumatol Int 2008;28:765-9.

25. Skoumal M, Haberhauer G, Kolarz G, Hawa G, Woloszczuk W, Klingler A, et al. The imbalance between osteoprotegerin and cathepsin $\mathrm{K}$ in the serum of patients with longstanding rheumatoid arthritis. Rheumatol Int 2008;28:637-41

26. Secchiero P, Corallini F, Pandolfi A, Consoli A, Candido R, Fabris $\mathrm{B}$, et al. An increased osteoprotegerin serum release characterizes the early onset of diabetes mellitus and may contribute to endothelial cell dysfunction. Am J Pathol 2006;169:2236-44.

27. Zauli G, Corallini F, Bossi F, Fischetti F, Durigutto P, Celeghini C, et al. Osteoprotegerin increases leukocyte adhesion to endothelial cells both in vitro and in vivo. Blood 2007;110:536-43.

28. Mangan SH, Van Campenhout A, Rush C, Golledge J. Osteoprotegerin upregulates endothelial cell adhesion molecule response to tumor necrosis factor-alpha associated with induction of angiopoietin-2. Cardiovasc Res 2007;76:494-505.

29. Khosla S, Arrighi HM, Melton LJ 3rd, Atkinson EJ, O'Fallon WM, Dunstan C, et al. Correlates of osteoprotegerin levels in women and men. Osteoporos Int 2002;13:394-9.

30. Lee CK, Lee EY, Chung SM, Mun SH, Yoo B, Moon HB. Effects of disease-modifying antirheumatic drugs and antiinflammatory cytokines on human osteoclastogenesis through interaction with receptor activator of nuclear factor kappa B, osteoprotegerin, and receptor activator of nuclear factor kappa B ligand. Arthritis Rheum 2004;50:3831-43.

31. Boyle WJ, Simonet WS, Lacey DL. Osteoclast differentiation and activation. Nature 2003;423:337-42.

32. Zauli G, Rimondi E, Stea S, Baruffaldi F, Stebel M, Zerbinati C, et al. TRAIL inhibits osteoclastic differentiation by counteracting RANKL-dependent p27Kip1 accumulation in pre-osteoclast precursors. J Cell Physiol 2008;214:117-25.

33. Zauli G, Rimondi E, Secchiero P. Soluble TRAIL does not impair the anti-osteoclastic activity of osteoprotegerin. J Cell Mol Med 2008;12:1063-5. 